\title{
Identification of quality markers of Xiaojin Pills using a combination of high-performance liquid chromatograph- tandem mass spectrometry and multivariate analysis
}

\author{
Xi Xiong ${ }^{1}$, Ya-nan He${ }^{1}$, Bi Feng ${ }^{1}$, Yuan $\mathrm{Pan}^{2}$, Xiu-mei Ke ${ }^{1}$, Li Han ${ }^{1 *}$, Ding-kun \\ Zhang $^{1 *}$, Yi Zhang ${ }^{3}$ \\ ${ }^{1}$ State Key Laboratory Breeding Base of Systematic Research, Development and Utilization of Chinese Medicine Resources, \\ ${ }^{2}$ Analysis \& Testing Center, Chengdu University of Traditional Chinese Medicine, ${ }^{3}$ Chengdu Institutes of Food and Drug \\ Control, Chengdu, 611137, PR China
}

*For correspondence: Email: 465790643@qq.com; Tel/Fax: +862861800127

Sent for review: 25 February 2018

Revised accepted: 20 July 2018

\begin{abstract}
Purpose: To establish an appropriate quality control method for Xiaojin pills using high-performance liquid chromatograph-tandem mass spectrometry combined with multivariate analysis.

Methods: High-performance liquid chromatograph-tandem mass spectrometry was established to detect and quantify 13 chemical components of Xiaojin Pills. In order to evaluate the quality difference between diverse specimens of Xiaojin Pills, several multivariate statistical techniques were applied to analyze the dissimilarity between different batches of samples, including principal composition analysis method and clustering methodology.

Results: Five chemical components were identified as primary quality markers, which can be used to accurately distinguish various samples and command the quality of Xiaojin Pills.

Conclusion: The results afford a professionally scientific basis for the quality monitoring of Xiaojin Pills and also furnishes reasonable ideas and suggestions for the quality control of other traditional drugs.

Keywords: Xiaojin Pills, HPLC-MS/MS, Quality control, Chemometrics, Quality markers

This is an Open Access article that uses a funding model which does not charge readers or their institutions for access and distributed under the terms of the Creative Commons Attribution License (http://creativecommons.org/licenses/by/4.0) and the Budapest Open Access Initiative (http://www.budapestopenaccessinitiative.org/read), which permit unrestricted use, distribution, and reproduction in any medium, provided the original work is properly credited.

Tropical Journal of Pharmaceutical Research is indexed by Science Citation Index (SciSearch), Scopus, International Pharmaceutical Abstract, Chemical Abstracts, Embase, Index Copernicus, EBSCO, African Index Medicus, JournalSeek, Journal Citation Reports/Science Edition, Directory of Open Access Journals (DOAJ), African Journal Online, Bioline International, Open-J-Gate and Pharmacy Abstracts
\end{abstract}

\section{INTRODUCTION}

Nowadays, with the rapid development of the society and the changes in physical environment as well as the accelerating the pace of life, diseases related to breast are serious threats women's health [1]. Hyperplasia of mammary glands (HMG) has a high incidence and high recurrence rate, affecting middle-aged woman.
The incidence of breast cancer in patients with hyperplasia of mammary glands is 2 - 4 times higher than in healthy people $[2,3]$. Nevertheless, the pathogenesis of HMG is not clear and suitable treatments are restricted [4]. Although conventional hormone therapy has some benefits, it may lead to recurrent endocrine system disease. Clinicians in China often treat HMG with Chinese patent medicine and Western medicine. Xiaojin Pills is the first choice of 
proprietary Chinese medicine for HMG, a classical medical prescription with a history of more than 200 years.

Xiaojin Pills has the effects of blood circulation, detumescence and alleviating pain. The overall regulation, multi target and channel interaction model offer a good curative effect $[5,6]$. A metaanalysis of 858 cases with HMG receiving routine preparation of western medicine therapies together with Xiaojin Pills showed their overall response rate and recovery rate dramatically exceed the matched group with no significant side effect [7]. Furthermore, clinical researches have indicated that Xiaojin Pills have an obvious treatment effect in disease of prostate, [8] a joint pain, thyroid nodule, breast cancer and other cancers $[9,10]$. Due to its dependable therapeutic effect, Xiaojin Pills was first recorded in Chinese pharmacopoeia of the 1977 edition and subsequently improved pills standards in all other versions.

Xiaojin Pills contain 10 kinds of traditional Chinese medicine materials, involving Aconiti Kusnezoffii Radix Cocta, Moschus, Fragrant Ink, Liquidambaris Resina, Momordicae Semen, Angelicae Sinensis Radix, Faeces Trogopterori, Olibanum, Myrrha, and Lumbricus rubellus. The sources of these medicinal materials are complicated, including botanic, resinous, mineral and creatural medicine. The variation in the quality of natural medicines is extremely significant, and many factors are known to affect it. For these medicines, single quality control cannot objectively and truly reflect the difference in quality. The overall quality control strategy is often considered to be a better solution and can reflect the quality of the drug comprehensively and objectively. However, Chinese Pharmacopeia 2015 only stipulated the minimum margin of muscone to ensure the effectiveness of the pills and the identification of diester diterpenoid alkaloids by thin layer chromatography to get command of toxicity. These tests cannot completely control the quality of Xiaojin Pills Thus, it is crucial to build a comprehensive quality control way for Xiaojin Pills.

In the current research, a fast, yare, and exact HPLC-MS/MS analysis was built for the detection of 13 active or toxic chemical components directed by six traditional Chinese medicinal materials, containing Levistilide A (Lev), Benzoylaconitine (BAC), Inosine (Ino), Benzoylhypacoitine (BHA), Ligustilide (Lig), Benzoylmesaconitine (BMA), Acetyl-11-keto-bboswellic acid (Ace), Aconitine (AC), BetaBoswellic acid (Bet), Hypaconitine (HA),
Mesaconitine (MA), Protocatechuate (Pro) and Ferulic Acid (Fer). Main methodological technical specifications of the HPLC-MS/MS assay, such as repeatability, sensibility, linearity and accuracy were research systematically [11]. The 21 batches of Xiaojin Pills obtained from four factories were appraised using the method we developed. Incorporating with chemometrics resolutions, the results were analyzed. The chemical markers that affect products quality were singled out, suggesting improvements in quality consistency. Figure 1 exhibits the experimental process. It is hoped that our research could supply a newfangled method for Xiaojin Pills' quality control to guarantee its security and curative effects.

\section{EXPERIMENTAL}

\section{Stuffs and agentia}

21 passels of Xiaojin Pills' samples were obtained from 4 manufacturers (named A, B, C and $D$ ) and their related messages are shown in Table 1.

Ammonium and formic acid of HPLC-grade were obtained from KeLong Chemical Factory (Chengdu, China). From Fisher Chemical Company (Pittsburg, USA), HPLC-grade methanol and acetonitrile were acquired. The ultra-pure grade water we used was acquired by water depuration system of Millipore Milli-Q (Millipore, China). $0.22 \mu \mathrm{m}$ membranes (Jinteng, China) were used to filter every sample solution before use during the experiment.

Reference substances of Hypaconitine (HA, MUST-16032106), Benzoylaconine (BAC, CHB160912), Mesaconitine (MA, MUST16032504), Beta-boswellic acid (Bet, CHB 170801), Benzoylhypaconine (BHA, CHB160326), Aconitine (AC, MUST-16062206), and Benzoylmesaconine (BMA, CHB151203), were provide by Chroma-Biotechnology Co., Ltd (Chengdu, China). Reference substances of Protocatechuate (Pro, 15121808), Ligustilide (Lig, PRF 15092501), Ferulic acid (Fer, PRF7101144) and Acetyl-11-keto-b-boswellic acid (Ace, PRF8051801) were produced by Biopurify Phytochemicals Ltd (Chengdu, China). Chengdu PureChem-Standard Co., Ltd (Chengdu, China) provided us with their Inosine (Ino, 151014). Reference substance of Levistilide A (Lev, PSO756-0010) was a product from PUSH Bio-Technology Co., Ltd (Chengdu, China). All these reference substances' purity is surpassed $98 \%$ and their chemical structural formulas were showed in Figure 2. 


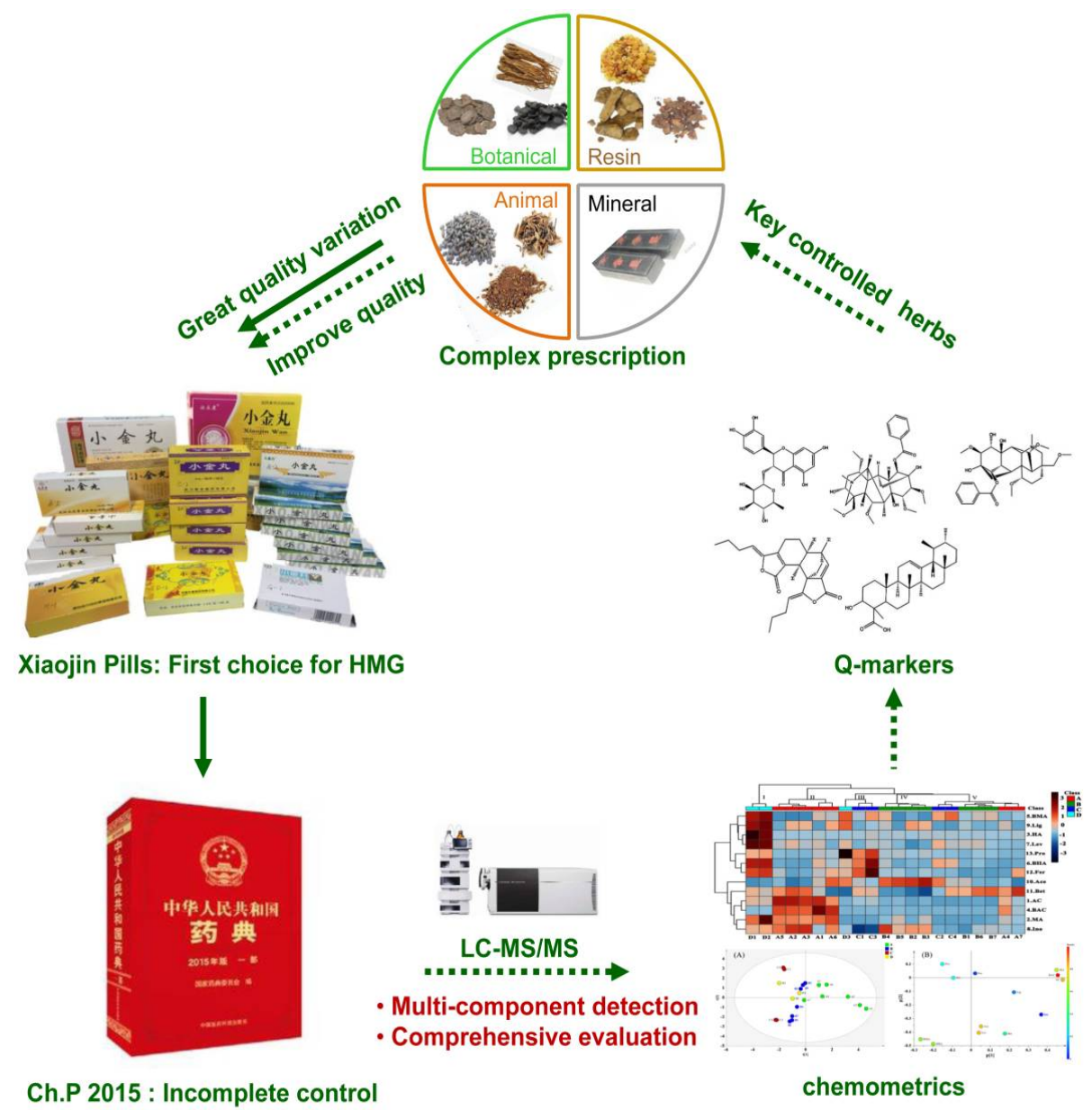

Figure 1: Filtrating procedure for Xiaojin Pill's quality Markers
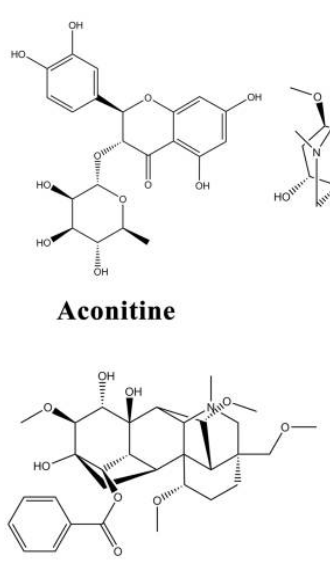

Benzoylhypacoitine

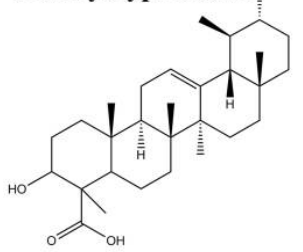

Beta-Boswellic acid

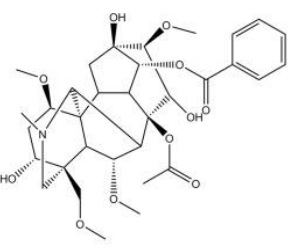

Mesaconitine

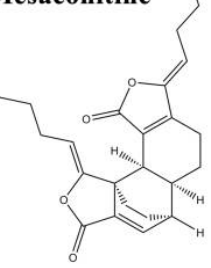

Levistilide A<smiles>COc1cc(/C=C/C(=O)O)ccc1O</smiles>

Ferulic acid
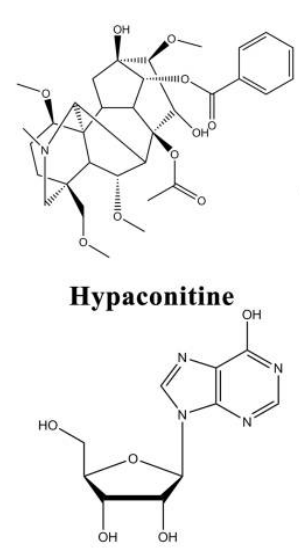

Inosine<smiles>O=C(O)c1ccc(O)c(O)c1</smiles>

Protocatechuate
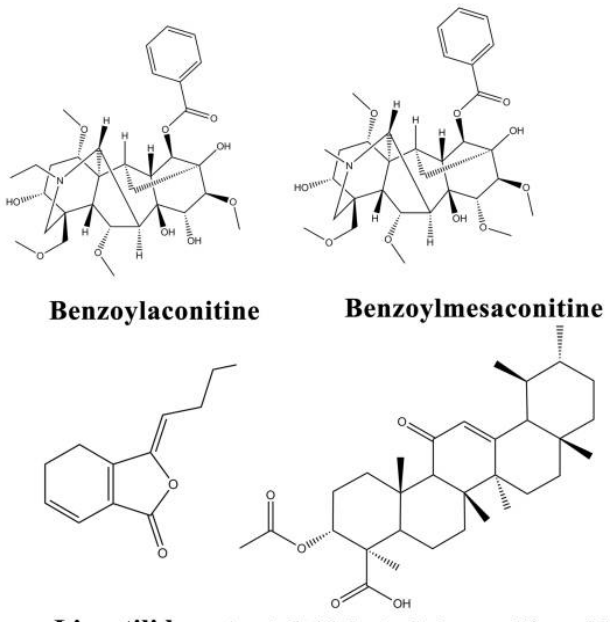

Ligustilide Acetyl-11-keto-b-boswellic acid

Figure 2: Chemical structure of the 13 compounds examined in this study 


\section{HPLC-MS/MS analysis}

\section{MS criteria}

An Agilent6460C triple-quadrupole system (Agilent Technologies, USA) and Agilent1260 high performance liquid chromatograph were used to analyze our specimens, with a column which model was Zorbax Eclipse XDB-C18 column $(5 \mu \mathrm{m}, 150 \mathrm{~mm} \times 4.6 \mathrm{~mm}$ ) (Agilent Technologies). The temperature of the column was 30 degree centigrade and the injection volume of sample was $0.1 \mu \mathrm{L}$. The constituent part of the moving phase was (A) $10 \mathrm{~m} \mathrm{~mol} / \mathrm{L}$ ammonium acid for the mode of $\mathrm{ESI}^{-}$or $0.1 \%$ aqueous formic acid in water for the mode of $\mathrm{ESI}^{+}$with the gradient elute being used for 0 $20 \% \mathrm{~A}$ for $0-1 \mathrm{~min}, 20-50 \% \mathrm{~A}$ for $1-2 \mathrm{~min}, 50$ $-70 \%$ A for $2-3 \min , 70-20 \%$ A for $3-5 \mathrm{~min}$, $20-0 \% A$ for $5-30 \mathrm{~min}$. The moving phase of $B$ is acetonitrile and the flow velocity was 0.3 $\mathrm{ml} / \mathrm{min}$.

Using negative ion mode and positive ion mode with the $100-1000 \mathrm{~m} / \mathrm{z}$ scanning interval, mass spectrometric scan were received. The major parameters of MS were as follows: atomizing pressure, $15 \mathrm{psi}(1 \mathrm{psi}=6.895 \mathrm{Kpa})$; arger, 35 psig; gas temperature, 300 degrees; capillary voltage, $4000 \mathrm{~V}$; gas flow rate, $11 \mathrm{~L} \cdot \mathrm{min}-1$.

The MS parameters of all samples and their multiple reaction monitoring transitions are displayed in Table 2. For this case, each chemical component's MRM chromatogram is exhibited in Figure 3.

\section{Preparation of reference solutions}

The reference solution including $1.12 \mu \mathrm{g} / \mathrm{mL}$ BAC, $1.27 \mu \mathrm{g} / \mathrm{mL}$ AC, $1.03 \mu \mathrm{g} / \mathrm{mL}$ BMA, 1.02 $\mu \mathrm{g} / \mathrm{mL}$ MA, $0.90 \mu \mathrm{g} / \mathrm{mL}$ BHA, $0.97 \mu \mathrm{g} / \mathrm{mL}$ HA, $0.96 \mu \mathrm{g} / \mathrm{mL}$ Bet, $0.96 \mu \mathrm{g} / \mathrm{mL}$ Lev, $0.98 \mu \mathrm{g} / \mathrm{mL}$ Pro, $0.998 \mu \mathrm{g} / \mathrm{mL}$ Lig, $1.09 \mu \mathrm{g} / \mathrm{mL}$ Ace, 1.013 $\mu \mathrm{g} / \mathrm{mL}$ Fer and $1.03 \mu \mathrm{g} / \mathrm{mL}$ Ino was prepared and stored in a glass measuring flask and dissolved in $10 \mathrm{~mL}$ methanol. Stored these reference solutions we prepared in brown glass containers at 4 degrees and stabilized for at least 7 days. The reference solution was prepared freshly by diluting an appropriate amount of the reference solution with methanol.

\section{Preparation of test solutions}

Different batches of Xiaojin Pills were crushed to powder and passed through the five-sieve. The dosage of powder in each sample was precisely weighed $(0.2 \mathrm{~g})$, and then extracted by ultrasonic extraction method for 50 min in 35 degrees with $5 \mathrm{ml}$ methanol. After the extracting solution was cooled down, it was used to be filtered through a $0.22 \mu \mathrm{m}$ microfiltration membrane. Then we obtained the test solution.

\section{Method validation}

In the case of linearity, the $\mathrm{ICH}$ guide has verified the detection limits (LOD) and quantitative limits (LOQ), repeatability, stability, recovery and precision methods for the HPLC-MS/MS method [12].

Table 1: Source and serial number of each passel sample

\begin{tabular}{lclc}
\hline Item no. & Batch no. & Item no. & Batch no. \\
\hline A1 & 151201 & B5 & 150601.1 \\
A2 & 160114 & B6 & 161102 \\
A3 & 160115 & B7 & 161201 \\
A4 & 151105 & C1 & 20151003 \\
A5 & 160310 & C2 & 20160501 \\
A6 & 150905 & C3 & 20151002 \\
A7 & 150705 & C4 & 20160502 \\
B1 & 160501.1 & D1 & 151009 NO.015 \\
B2 & 160601 & D2 & 151008 NO.198 \\
B3 & 150801.2 & D3 & 160806 NO.073 \\
B4 & 151102 & & \\
\hline
\end{tabular}


Table 2: The conclusion of the monitoring ion, product ion, precursor ion, molecular weight, CE and DP of the 13 chemical components

\begin{tabular}{ccccccc}
\hline Compound & $\begin{array}{c}\text { Molecular } \\
\text { weight }\end{array}$ & $\begin{array}{c}\text { Monitoring } \\
\text { ion }\end{array}$ & $\begin{array}{c}\text { Precursor ion } \\
(\mathbf{m} / \mathbf{z})\end{array}$ & $\begin{array}{c}\text { Product ion } \\
(\mathbf{m} / \mathbf{z})\end{array}$ & DP $(\mathrm{V})$ & CE $(\mathrm{eV})$ \\
\hline $\mathrm{AC}$ & 645.7 & $\mathrm{ESI}^{+}$ & 646.3 & 105.1 & 180 & 50 \\
$\mathrm{MA}$ & 631.7 & $\mathrm{ESI}^{+}$ & 632.2 & 105.1 & 180 & 46 \\
HA & 615.7 & $\mathrm{ESI}^{+}$ & 616.3 & 105.0 & 180 & 46 \\
BAC & 603.7 & $\mathrm{ESI}^{+}$ & 604.3 & 105.0 & 180 & 45 \\
BMA & 589.7 & $\mathrm{ESI}^{+}$ & 590.3 & 105.0 & 205 & 46 \\
BHA & 573.3 & $\mathrm{ESI}^{+}$ & 574.3 & 105.0 & 200 & 46 \\
Lev & 380.2 & $\mathrm{ESI}^{+}$ & 381.0 & 191.0 & 90 & 10 \\
Ino & 268.2 & $\mathrm{ESI}^{+}$ & 268.9 & 136.9 & 80 & 5 \\
Lig & 190.2 & $\mathrm{ESI}^{+}$ & 191.0 & 90.9 & 100 & 15 \\
Ace & 512.4 & $\mathrm{ESI}^{-}$ & 511.3 & 59.1 & 110 & 12 \\
Bet & 456.4 & $\mathrm{ESI}^{-}$ & 455.3 & 377.4 & 110 & 48 \\
Fer & 194.1 & $\mathrm{ESI}^{-}$ & 193.0 & 133.8 & 100 & 12 \\
Pro & 154.0 & $\mathrm{ESI}^{-}$ & 153.0 & 109.0 & 90 & 12 \\
\hline
\end{tabular}

The peak area of each component in diverse concentration gradient solutions was determined, and the standard curve was established. Standard solutions were prepared and diluted to $2,5,10,20,50$ and 100 times respectively with methanol. The different concentration gradient solutions were injected with 3 times, and the correlation coefficients of the 13 compounds were determined by linear multiple regression. By analyzing a battery of diluted solutions, the LOQ and LOD for the detecting chemical components were calculated at signal-to-noise $(\mathrm{S} / \mathrm{N})$ ratios of 10 and 3 separately.

The accuracy of the peak area measurement for the 13 chemical components of relative standard deviations (RSDs) was calculated by six reduplicative injections. The sample stability was monitored by analyzing the same test solution every 4 for $24 \mathrm{~h}$. The 13 chemical components' measurements' RSDs were considered to be an indicator of the stability for the analytical system. 6 replicate samples were prepared in one day and the reproducibility of this method was estimated by detecting those samples.

On the same day, the recovery rates of the 13 chemical components were detected by method of standard addition. The mixed reference solution was added in the Xiaojin Pills samples and under the same conditions, the differences between un-spiked and spiked samples were analyzed, then the recovery results were calculated by these differences.

\section{Cluster analysis (CA)}

CA is a multi-analysis for grouping samples [13]. By Metabo Analyst 3.0, the CA of samples was operated in this research. Clusters were built by fusion rules and squared Euclidean distance. In order to materialize the differences and similarity of the different batches of samples, every data was represented as a temperature chart.

\section{Principle component analysis (PCA)}

PCA is diffusely applied to reduce the multivariate problems. By reducing the correlation relationships between a large variables' numbers based on a small number of potential essentials and minimizing the information loss, the dimensionality of the original data can be reduced $[14,15]$. In this research, SIMCA-P 13.0 (Umetrics, Umea, Sweden) was used to carry out PCA for the standardized concentrations of all 13 chemical components. With the help of PCA loading plots, the main chemical markers were found and they have the significance on distinguish of samples in different parts. 


\section{RESULTS}

\section{Method validation}

The regression equation for the 13 chemical components showed a good linear relationship $(R>0.99)$. The linear ranges, regression equation, LOQ, LOD and the RSD of the precision, repeatability, stability and recovery are exhibited in Tables 3 and 4 . For the 13 components, the precision ranged of RSD is 0.24 - $3.39 \%$, the RSD range of stability is $0.73-4.44$ $\%$, and the repeatability of RSD was under 4.57 $\%$. The range of the recovery study is 93.95 $101.35 \%$, and the RSD range of corresponding is $1.30-4.62 \%$. By analyzing the figures above, we believed this analytical means satisfied our needs.

\section{Clustering analysis (CA) consequence}

By measuring the 3 kinds of diester alkaloid, it is indicated that Xiaojin Pills' safety could be guaranteed. Using the concentration of the 13 components in 21 batches of samples, a $13 \times 21$ matrix was generated, and all the values were shown in thermal imaging. The results of $C A$ clearly show the difference of 13 components' contents as shown in Figure 4, which clearly reveals the difference of thirteen chemical components' contents. Using a proper distance degree, we classified the samples into four clusters. Cluster I consisted of samples required from factory $D$ and the information of Cluster II was mainly come from manufacture A. Cluster III, IV and $V$ were mainly constituted from the samples obtained from manufacture $B$ and $C$, and some samples were from manufacture $A$ and D. On the basis of the thermal map, the chemical components of Lev, HA, Lig, BMA, Pro, Fer and BHA in samples from manufacture $D$ were significantly different from other batches. With respect to the total content of 13 chemical compounds under study, it could be found out that the supreme contents of the Bet, AC, BMA, MA and Ino existed in cluster II. The samples' qualities required from manufactory $D$ and manufactory $A$ were quite different from other manufactories. The distance between the samples from manufactory B was the shortest, indicating that the samples obtained from manufactory $B$ were more semblable.

Table 3: Regression equations, linear ranges, correlation of association, LOQ and LOD of thirteen chemical components

\begin{tabular}{lccccc}
\hline Compound & Regression equation & $\mathbf{r}$ & $\begin{array}{c}\text { Liner range } \\
(\mathbf{\mu g} / \mathbf{m L})\end{array}$ & $\begin{array}{c}\text { LOQ } \\
(\mathbf{n g} / \mathbf{m L})\end{array}$ & $\begin{array}{c}\text { LOD } \\
(\mathbf{n g} / \mathrm{mL})\end{array}$ \\
\hline AC & $y=2145.4 x+36.095$ & 0.9979 & $0.0127 \sim 2.5400$ & 0.79 & 3.20 \\
MA & $y=5607.3 x+257.41$ & 0.9990 & $0.0515 \sim 10.3000$ & 0.77 & 2.91 \\
HA & $y=24474 x+275.3$ & 0.9990 & $0.0024 \sim 0.2425$ & 0.70 & 2.70 \\
BAC & $y=119045 x-2953.6$ & 0.9989 & $0.0560 \sim 11.2000$ & 0.71 & 2.91 \\
BMA & $y=27340 x-17448$ & 0.9990 & $0.0155 \sim 3.0900$ & 0.74 & 3.09 \\
BHA & $y=74457 x-16811$ & 0.9986 & $0.0225 \sim 4.5000$ & 0.025 & 10.167 \\
Lev & $y=456.7 x+1273.4$ & 0.9995 & $0.0024 \sim 0.4800$ & 0.75 & 2.4 \\
Ino & $y=13773 x+1292.9$ & 0.9989 & $0.0206 \sim 4.1200$ & 10.3 & 25.75 \\
Lig & $y=1489.6 x+348.78$ & 0.9979 & $0.0399 \sim 7.9840$ & 3.99 & 15.9 \\
Ace & $y=960.23 x+2093.1$ & 0.9999 & $1.6600 \sim 261.6000$ & 10.9 & 21.0 \\
Bet & $y=149.82 x+0.9763$ & 0.9996 & $0.1920 \sim 9.6000$ & 9.6 & 18.2 \\
Fer & $y=809.46 x-844.63$ & 0.9979 & $0.4025 \sim 10.1300$ & 5.05 & 10.13 \\
Pro & $y=27059 x-30549$ & 0.9997 & $0.9600 \sim 78.4000$ & 1.01 & 11.3 \\
\hline
\end{tabular}


Table 4: Accuracy, repeatability, stability and recovery results

\begin{tabular}{|c|c|c|c|c|c|c|}
\hline \multirow{2}{*}{$\begin{array}{l}\text { Compound } \\
A C\end{array}$} & \multirow{2}{*}{$\begin{array}{c}\begin{array}{c}\text { Precision } \\
\text { RSD/\% }\end{array} \\
3.3640\end{array}$} & \multirow{2}{*}{$\begin{array}{c}\begin{array}{c}\text { Stability } \\
\text { RSD/\% }\end{array} \\
3.2928\end{array}$} & \multirow{2}{*}{$\begin{array}{c}\begin{array}{c}\text { Mean mass } \\
\text { fraction } /(\mu \mathrm{g} / \mathrm{g})\end{array} \\
6.46689\end{array}$} & \multirow{2}{*}{$\begin{array}{c}\begin{array}{c}\text { Repeatability } \\
\text { RSD } / \%\end{array} \\
4.5694\end{array}$} & \multicolumn{2}{|c|}{$\begin{array}{c}\text { Recovery } \\
\text { Mean\% } \\
\text { RSD\% }\end{array}$} \\
\hline & & & & & 97.9152 & 4.4272 \\
\hline MA & 0.4659 & 4.2232 & 3.039625 & 2.4692 & 101.0089 & 1.7854 \\
\hline $\mathrm{HA}$ & 0.9975 & 3.0929 & 1.659989 & 3.5398 & 94.8169 & 1.5827 \\
\hline BAC & 2.1764 & 1.7638 & 2.633601 & 1.1302 & 101.3509 & 3.8486 \\
\hline BMA & 0.8331 & 1.1637 & 44.33336 & 1.4464 & 93.9479 & 1.4527 \\
\hline $\mathrm{BHA}$ & 0.9154 & 0.7265 & 8.60241 & 1.1302 & 97.6298 & 3.5634 \\
\hline Lev & 3.3876 & 2.5649 & 8.263625 & 4.0209 & 98.4893 & 1.2965 \\
\hline Ino & 0.8564 & 2.9342 & 14.24125 & 1.2889 & 104.3326 & 3.9750 \\
\hline Lig & 0.9975 & 2.9542 & 136.7232 & 3.5398 & 94.8149 & 1.5823 \\
\hline Ace & 0.2443 & 2.1030 & 777.9819 & 2.3147 & 96.7938 & 2.2396 \\
\hline Bet & 0.7899 & 4.4444 & 311.1656 & 3.6545 & 96.5429 & 2.0098 \\
\hline Fer & 2.9372 & 2.0542 & 34.43794 & 1.0415 & 95.7964 & 2.3422 \\
\hline Pro & 3.3840 & 0.8219 & 31.04584 & 0.5876 & 96.9143 & 4.6163 \\
\hline
\end{tabular}

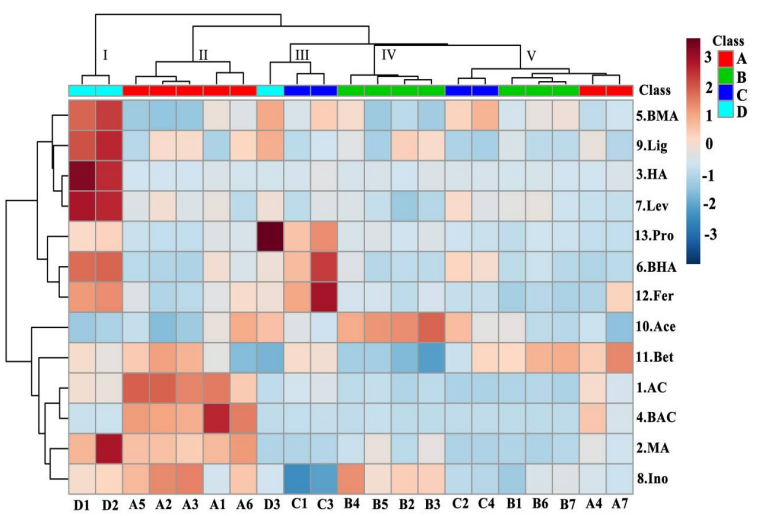

Figure 4: The CA results of different batches of Xiaojin pills

\section{Principle component analysis (PCA) consequences}

As a celebrated science, PCA is applied for decreasing the dimension of datum.

It permits for the visualization of dataset information in a several major components, and preserves the greatest variability in the group. Hence, PCA is used to release the computational burden. PCA was used to analyze the thirteen quantitative parameters. The score map (Figure $5 A$ ), in which each circle stood for a batch, demonstrated the distinct differentiation of the four factories' samples and shows that the
Euclidean distance between the samples from manufacturer $B$ is adjacent, confirming the $C A$ analysis result. For the factory $A$, the Euclidean distance between several samples is large, indicating that the Xiaojin Pills of factory A can be clearly distinguished from other factories existing some distinctions between the samples from factory A. PCA loading diagrams between the samples of factory $A$ indicating that the distance of BMA, Lev, BHA, Bet and AC is different from origin, which means that these components can play an important role in distinguishing the Xiaojin Pills from different batches. The quality of Xiaojin Pills can be controlled by controlling the contents of these five compounds.

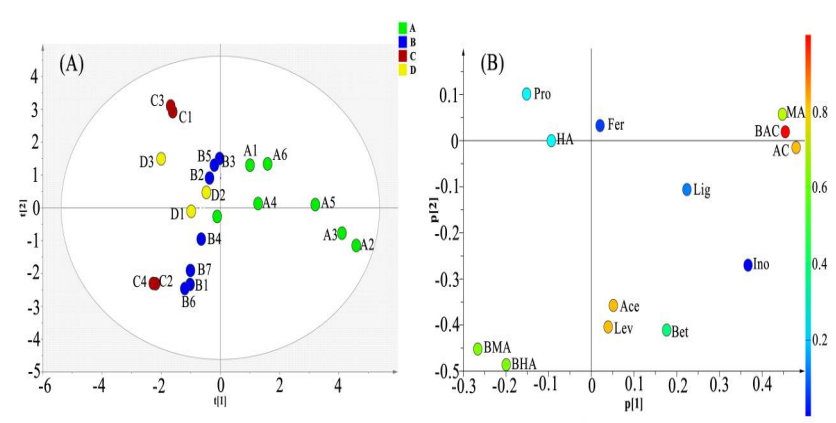

Figure 5: The scores plot $(A)$ of Xiaojin Pills samples from 4 factories. The loading plot $(B)$ for the common components

Trop J Pharm Res, August 2018; 17(8): 1669 


\section{DISCUSSION}

In this research, we investigated and contrasted different chromatographic conditions, including flow phases, gradient elution conditions and different columns to obtain high detection sensitivity, good separation degree, short running time and symmetric peak shapes. Three types of columns are as follows: Kromasil C18 column (5 $\mu \mathrm{m}, 200 \mathrm{~mm}$ ' $4.6 \mathrm{~mm}$ ), Agilent Technologies Zorbax Eclipse XDB-C18 (5 $\mu \mathrm{m}, 150 \mathrm{~mm} \times 4.6$ $\mathrm{mm}$ ) and Phenomenonex Gemini C18 column (5 $\mu \mathrm{m}, 150 \mathrm{~mm} \times 4.6 \mathrm{~mm}$ ). These columns were checked separately. Compared to other columns, the Agilent Technologies Zorbax Eclipse XDBC18 column possessed fine degree of peak separation as well as sharp peaks. The peak was poorly distinguished when methanol was used as the organic solvent of the mobile phase. Nevertheless, the resolution was greatly improved by replacing methanol with acetonitrile. As acetonitrile replaced methanol, it improved the resolution significantly. We added various concentration gradient of acetic acid $(0.05,0.1$, and $0.2 \%)$ or formic acid $(0.05,0.1$, and $0.2 \%)$ to the water phase, separately. When $0.1 \%$ formic acid was measured, the peak shape and best response were obtained and then selected for the study. The overall run time of the chromatographic was $13 \mathrm{~min}$. In order to assure fine separation, the flow rate was $0.3 \mathrm{~mL} / \mathrm{min}$ and the column temperature was 30 degrees.

Use the reference compounds to optimized Mass spectral conditions in scan type of MRM. We collected the LC-MS/MS data by Agilent Triple Quadrupole mass spectrometer with an electrospray interface (ESI) operating in $\mathrm{ESI}^{+}$and $\mathrm{ESI}^{-}$. The ability of the chemical components to acquire or lose electrons decided the mode of ESI we chose [16]. To obtain a good reception, Fer, Ace, Pro and Bet, were detected by the $\mathrm{ESI}^{-}$mode, while AC, Ino, MA, Lig, HA, BAC, Lev, BMA, and BHA were tested by $\mathrm{ESI}^{+}$. Under the MRM mode, all compounds could be tested in different channels without interaction effect. Therefore, by this means of detection, we can sensitively and accurately measure the content of multi components simultaneously.

At the temperature of 35 degrees, the extraction efficiency was highest. In addition, extraction times ranging from 30 to 60 minutes were researched, with a time of 50 minutes indicated the supreme extraction efficiency. In conclusion, the results showed that the optimum extraction conditions were as follows: methanol dosage was $5 \mathrm{~mL}$ for $0.2 \mathrm{~g}$ powder, extraction temperature was 35 degrees, and extraction time was 50 minutes.
By the content assaying of the active constituents, the quality of Chinese patent medicine is mainly evaluated. Most proprietary Chinese medicines are produced by different factories (usually produced at the same time), which leads to quality fluctuations. These changes could seriously influence the curative effect of the medicine and even toxic side effects were caused. As a consequence, it is crucial to study the reasons for differences and build an appropriate method of quality control. Prof. Liu Chang-xiao (China) put forward the idea of quality markers (Q-markers) for natural medicine in 2016[17]. Q-markers should have certain basic characteristics. . There are certain basic characteristics that Q-markers should possess. Firstly, they are chemicals inherent in the products or generated in the process of productive. Secondly, they are closely related to the functional properties of natural medicine, and have a certain chemical structures. Meanwhile, they should be qualitatively identified and quantitatively measured. Finally, for natural medicines, these chemical components should reflect the quality of the product and can be applied to appraise the quality stability and consistency.

To control the Xiaojin Pills' quality comprehensively, 17 active ingredients were screened from eight herbs. In methodological studies, the four chemical components (oleanolic acid, mucosketone, papain, and malor,) were abandoned due to their too stable chemical structures and unexpected fragmentation behavior. Therefore, for quality control, we finally settled on 13 components. Bet and Ace are came from Myrrha and Olibanum, whose ethanol extracts have anti-inflammatory activities for various acute and chronic inflammation $[18,19]$. The extraction of Olibanum has the function of inhibiting the generation of 5-hydroxy-24eicosatetraenoic acid and leukotriene and reducing the forming of 5-lipoxygenase (5LOX)[18].

Ino derives from lumbricus rubellus with the function of anti-tumor, analgesic, antipyretic, and anti-inflammatory. It also contains growth factors that promote tissue repair [20]. Pro is found in Faeces Trogopterori and research has shown of its usefulness in reducing swelling and resolving mass [21] (resolving mass is the elimination of nodules and masses in various tissues of human body). Lev, Fer and Lig are the index constituent parts of the Angelicae Sinensis Radix which are effective in activating blood circulation and dissipating blood stasis [22]. AC, BAC, MA, BMA, $\mathrm{BHA}$ and $\mathrm{HA}$ are included in Aconiti Kusnezoffii 
Radix Cocta which has a mass of uses including antiepileptic, analgesic and anti-inflammatory [23-25].

Through the determination of 13 components in Xiaojin Pills of different batches combined with multivariate statistical analysis, five quality markers were screened out, including BMA, $\mathrm{BHA}, \mathrm{AC}$, Lev and Bet. The different sources of Xiaojin Pills could be identified by these ingredients (Q-markers) reflecting the inherent changeability of the Xiaojin Pills' quality and providing important methods to improve the quality of Xiaojin Pills. From the highly variable components of Olibanum, Aconiti Kusnezoffii Radix Cocta, Myrrha and Angelicae Sinensis Radix, it could be found that there is a great difference great difference exists in the selection of raw material selections and feeding stage in different factories. Establishing standard limits for the four medicinal materials can prominently improve the quality. On the basis of this study, establishing internal standards limits for Xiaojin Pills can significantly improve quality consistency.

\section{CONCLUSION}

In conclusion, this research explores the reasons for differences in quality, providing recommendations to improve the quality of medicine from pharmaceutical companies. The study provides ideas, analytical and statistical methods for the consistent evaluation of other types of preparations of ethnomedicinal origin.

\section{DECLARATIONS}

\section{Acknowledgement}

The analytical instruments were supported by Analysis and Test Center of Chengdu University of TCM. We thank the reviewers for their critical comments on the manuscript. This work was supported by the National Nature Science Foundation of China (no. 81274098 and no. 81873232).

\section{Conflict of Interest}

No conflict of interest associated with this work.

\section{Contribution of Authors}

The authors declare that this work was done by the authors named in this article and all liabilities pertaining to claims relating to the content of this article will be borne by them.

\section{REFERENCES}

1. Li P, Huang J, Wu H, Fu C, Li Y, Qiu J. Impact of lifestyle and psychological stress on the development of early onset breast cancer. Med 2016; 95: e5529.

2. Arthur R, Wang $Y$, Ye K, Glass AG, Ginsberg M, Loudig $O$, Rohan T. Association between lifestyle, menstrual/reproductive history, and histological factors and risk of breast cancer in women biopsied for benign breast disease. Breast cancer research and treatment 2017.

3. Wang L, Zhao D, Di L, Cheng D, Zhou X, Yang X, Liu Y. The anti-hyperplasia of mammary gland effect of thladiantha dubia root ethanol extract in rats reduced by estrogen and progestogen. J Ethnopharmacol 2011; 134: 136-140.

4. Wright JD, Desai VB, Chen L, Burke WM, Tergas Al, Hou $J Y$, Accordino M, Ananth CV, Neugut Al, Hershman DL. Utilization of gynecologic services in women with breast cancer receiving hormonal therapy. Am J Obstet Gynecol 2017; 217: 59.e51-59.e12.

5. Chen $H$, Mo $X, Y u J$ J, Huang Z. Alpinetin attenuates inflammatory responses by interfering toll-like receptor 4/nuclear factor kappa $b$ signaling pathway in lipopolysaccharide-induced mastitis in mice. Int Immunopharmacol 2013; 17: 26-32.

6. Das Gupta S, So JY, Wall B, Wahler J, Smolarek AK, Sae-Tan S, Soewono KY, Yu H, Lee MJ, Thomas PE et al. Tocopherols inhibit oxidative and nitrosative stress in estrogen-induced early mammary hyperplasia in aci rats. Mol carcinog 2015; 54: 916-925.

7. Sun $L Q$, Liu F, Chen WQ, et al. Systematic evaluation on Xiaojin Pill treatment of hyperplasia of mammary glands. Chin J Drug Evaluation 2016; 33: 448-456.

8. Qu XW, Zhang SW, Zhang PH, Yin J. Xiaojin wan inhibits the expression of cox-2 in prostate tissues of prostatitis pain rats. Zhonghua Nan Ke Xue 2008; 14: 759-762.

9. Zhou AG, Ding YX, Guo HY, Chen MF, Xiao BL, Jiang SJ. Experimental study on antitumor effect of Xiaojin Pills. Acta Universitatis Medicinalis Secondae Shanghai 1990; 10: 185-188.

10. Zheng YJ, Zhong MC, Meng $K X$, et al. Clinical observation of nodular goiter treated by Xiaojin pill combined with Euthyrox. Chinese Journal of surgery of Integrated Traditional and Western Medicine 2013; 19: 297-298.

11. Lee JT, Pao LH, Hsieh CD, Huang PW, Hu OYP. Development and validation of an $1 c-m s / m s$ method for simultaneous quantification of hesperidin and hesperetin in rat plasma for pharmacokinetic studies. Anal Methods 2017; 9: 3329-3337.

12. Products EAftEoM. Ich topic q2b. Validation of analytical procedures: methodology (CPMP/ICH/281/95) Step 4Consensus Guideline, 1996.6.

13. Kong WJ, Zhao YL, Xiao XH, Jin C, Li ZL. Quantitative and chemical fingerprint analysis for quality control of rhizoma coptidischinensis based on uplc-pad combined 
with chemometrics methods. Phytomedicine 2009; 16 950-959.

14. Kong W, Jin C, Xiao X, Zhao Y, Liu W, Li Z, Zhang P. Determination of multicomponent contents in calculus bovis by ultra-performance liquid chromatographyevaporative light scattering detection and its application for quality control. J Sep Sci 2010; 33: 1518-1527.

15. Liu $P$, Yu HS, Zhang LJ, Song XB, Kang LP, Liu JY, Zhang J, Cao M, Yu K, Kang TG. A rapid method for chemical fingerprint analysis of pan panax notoginseng powders by ultra performance liquid chromatography coupled with quadrupole time-of-flight mass spectrometry. Chin J Nat Med 2015; 13: 471-480.

16. Zheng L, Huo $X-K$, Wang $C$, Cong $H-J$, Xiang $T$, Wu B, Zhang B-J, Huang S-S, Zhang L, Ma X-C. Simultaneous determination of 14 components in shuanghua baihe tablets by ultrasonic-assisted extraction and hplcms/ms. Anal Methods 2016; 8: 3359-3365.

17. Liu C, Guo DA, Liu L. Quality transitivity and traceability system of herbal medicine products based on quality markers. Phytomedicine 2018; 44: 247-257.

18. Ammon HP. Boswellic acids and their role in chronic inflammatory diseases. Adv Exp Med Biol 2016; 928: 291-327.

19. Henkel A, Tausch L, Pillong M, Jauch J, Karas M, Schneider G, Werz O. Boswellic acids target the human immune system-modulating antimicrobial peptide II-37. Pharmacol Res 2015; 102: 53-60.
20. Trisina J, Sunardi $F$, Suhartono $M T$, Tjandrawinata $R R$. Dlbs1033, a protein extract from lumbricus rubellus, possesses antithrombotic and thrombolytic activities. $J$ Biomed Biotechnol 2011; 2011: 519652.

21. Li Q, Lu W, Lu X. Advances in the study of feces trogopterori. Zhongguo Zhong yao za zhi 1998; 23: 570573.

22. Ji P, Wei Y, Hua Y, Zhang X, Yao W, Ma Q, Yuan Z, Wen $Y$, Yang C. A novel approach using metabolomics coupled with hematological and biochemical parameters to explain the enriching-blood effect and mechanism of unprocessed angelica sinensis and its 4 kinds of processed products. J Ethnopharmacol 2017; 211: 101 116.

23. Nyirimigabo E, Xu Y, Li Y, Wang Y, Agyemang $K$, Zhang $Y$. A review on phytochemistry, pharmacology and toxicology studies of aconitum. I Pharm Pharmacol 2015; 67: 1-19.

24. Tai CJ, El-Shazly M, Wu TY, Lee KT, Csupor D, Hohmann J, Chang FR, Wu YC. Clinical aspects of aconitum preparations. Planta Med 2015; 81: 10171028.

25. Wu J, Li C, Yuan W. Effects of shenfu injection on macrocirculation and microcirculation during cardiopulmonary resuscitation. J Ethnopharmacol 2016; 180: 97-103. 